\title{
Terminalidade da vida: reflexão bioética sobre a formação médica
}

Izaura Mariana Sobreiro ${ }^{1}$, Priscelly Cristina Castro Brito ${ }^{1}$, Adriana Rodrigues dos Anjos Mendonça ${ }^{1}$

1. Universidade do Vale do Sapucaí, Pouso Alegre/MG, Brasil.

\begin{abstract}
Resumo
Nesta pesquisa qualitativa, utilizou-se o método do discurso do sujeito coletivo para conhecer os significados, sentimentos e percepções de estudantes de medicina sobre o tema morte e pacientes terminais. Foram entrevistados 60 alunos de uma universidade do Sul de Minas Gerais. Para os significados sobre terminalidade da vida, a ideia central mais frequente foi "fechamento da vida". Quando o tema abordado foi o sentimento a respeito do paciente terminal, emergiram as ideias centrais "insegurança", "impotência", "frustração" e "angústia". Quanto ao preparo para lidar com a morte e o morrer, prevaleceu a ideia "não estou preparado". Já com relação à presença desses temas na formação, surgiram as ideias "abordagem superficial", "deveriam ser abordados com mais frequência" e "não abordados". Conclui-se que a formação médica não trata da inexorabilidade da morte, o que afasta a possibilidade de repensar o cuidado como forma terapêutica.
\end{abstract}

Palavras-chave: Bioética. Morte. Educação médica. Empatia.

\section{Resumen}

Terminalidad de la vida: reflexión bioética sobre la formación médica

En esta investigación cualitativa se utilizó el método del discurso del sujeto colectivo para conocer los significados, sentimientos y percepciones de los estudiantes de medicina sobre el tema muerte y pacientes terminales. Se entrevistó a 60 alumnos de una universidad del sur del estado de Minas Gerais, Brasil. En lo que respecta a los significados sobre la terminalidad de la vida, la idea central más frecuente fue "cierre de la vida". Cuando se abordó el sentimiento respecto al paciente terminal, surgieron como ideas centrales: "inseguridad", "impotencia", "frustración" y "angustia". En cuanto a la preparación para enfrentarse a la muerte y al morir, prevaleció la idea "no estoy preparado". A su vez, respecto a la presencia de estos temas durante la formación, surgieron las ideas "enfoque superficial", "deberían abordarse con más frecuencia", y "no abordados". Se concluye que la formación médica no aborda la inexorabilidad de la muerte, lo que aparta la posibilidad de repensar el cuidado como forma terapéutica.

Palabras clave: Bioética. Muerte. Educación médica. Empatía.

\section{Abstract}

\section{End of life: bioethical reflection on medical education}

This qualitative study used the collective subject discourse method to identify the meanings, feelings and perception of medical students about death and terminally ill patients. In total, 60 students from a medical school in southern Minas Gerais were interviewed. For the meanings about end of life, the most common idea was "closure of life." When the topic addressed was the feeling about terminal patients, the central ideas were "insecurity," "impotence," "frustration" and "anguish." Regarding the preparation to deal with death and dying, "unpreparedness" was the most common. When considering how these themes are approached during training, "superficial approach," "not very frequent" and "not addressed" emerged as ideas. We can thus conclude that the inexorability of death is not part of medical training, removing the possibility of rethinking care as a therapeutic form.

Keywords: Bioethics. Death. Medical education. Empathy. 
Durante milênios, a postura da humanidade diante da mortalidade foi de resignação. Exceto nas guerras ou em expedições de caça, saque ou conquista de territórios, a morte acontecia em contexto familiar; o enfermo morria em sua casa, rodeado pela família e amigos. Contudo, a partir do século XIX, os avanços da medicina aumentaram a expectativa de vida e a reversibilidade de muitas doenças contagiosas ${ }^{1}$. Dessa forma, o conhecimento biológico e os avanços tecnológicos tornaram a morte mais problemática, fonte de dilemas éticos e escolhas difíceis, geradoras de angústia e incerteza. Nesse contexto, no século XX, surge a bioética, campo do conhecimento que contribui para que o profissional repense o seu papel fundamental na saúde ${ }^{2}$.

Desde os primeiros anos da graduação, o estudante de medicina é induzido a valorizar os fundamentos técnico-científicos da profissão, deixando em segundo plano a concepção holística de ser humano e vida ${ }^{3}$. Assim, sentimentos de ansiedade ou angústia ante à inevitabilidade da morte, caso eventualmente surjam, são suplantados em prol da formação ${ }^{4}$. A formação médica segue a crise geral da educação, cada vez mais voltada à tecnicidade do mundo pós-moderno, ávido por seres humanos dotados de um saber especializado e utilitarista ${ }^{5}$. Nesse tipo de ensino, dimensões da existência humana - como a dimensão estética, a emocional, a fisiológica - são todas suplantadas pelo domínio mercadológico.

A educação é um processo de formação humana, e a pessoa humana é tema central da bioética. Portanto, além de possibilitar um saber técnico, a educação médica deveria contribuir para que futuros profissionais estabelecessem relações mais humanizadas e afetivas com seus pacientes. Diante da escassez de reflexões sobre a terminalidade da vida no contexto médico acadêmico, a presente pesquisa analisa o discurso de estudantes a fim de conhecer suas experiências e percepções sobre a morte, a fim de compreender em que medida estão familiarizados com o tema.

\section{Método}

$\mathrm{O}$ artigo traz resultados de estudo qualitativo, descritivo, transversal, não controlado, com amostragem intencional. O método utilizado, do discurso do sujeito coletivo (DSC), busca dar voz ao grupo pesquisado, propondo que tal discurso expressa o pensamento da coletividade. O tempo verbal tem de ser o tempo daquele que fala, o "eu", já que a representação social expressada pelo DSC agrega sujeitos e narrativas diversas, ainda que semanticamente semelhantes ${ }^{6}$.

\section{População-alvo e amostra}

A população do estudo envolveu estudantes do primeiro ao sexto ano do curso de medicina da Universidade do Vale do Sapucaí (Univás), em Pouso Alegre, Minas Gerais. A amostragem intencional desconsiderou sexo ou idade, utilizando apenas a lista de alunos matriculados em cada ano. Foram selecionados 10 estudantes de cada ano, totalizando 60 indivíduos - uma amostra significativa, correspondente a $12,5 \%$ do total de alunos.

\section{Instrumentos de pesquisa}

Foram usados como instrumento de pesquisa um questionário sociodemográfico (com as variáveis ano do curso, sexo, idade e religião) e um questionário semiestruturado, com quatro perguntas sobre o tema terminalidade da vida, formuladas com base na teoria das representações sociais. Essa teoria, fundamentada em um conhecimento socialmente elaborado e partilhado, associa a atividade mental de indivíduos e grupos para determinar a posição dos sujeitos em relação a situações e acontecimentos que lhes dizem respeito. As quatro perguntas do questionário eram: 1) "Para você, qual o significado de terminalidade da vida?"; 2) "Qual seria o seu sentimento se tivesse que lidar, neste momento, com um paciente terminal?"; 3) Se alguém lhe perguntasse se você se sente preparado(a) para lidar com a morte e o processo de morrer, o que você diria?" 4) "Se alguém Ihe perguntasse sobre a abordagem do tema da morte e pacientes terminais na formação médica, o que você diria?".

\section{Análise dos dados}

Os dados coletados pelo questionário sociodemográfico foram submetidos à análise descritiva. Para analisar os dados obtidos por meio do instrumento semiestruturado, utilizou-se o DSC, redigido na primeira pessoa do singular e composto por 
expressões-chave que apresentaram as mesmas ideias centrais e a mesma ancoragem.

\section{Procedimentos éticos}

A presente pesquisa obedeceu aos preceitos éticos estabelecidos pela Resolução do Conselho Nacional de Saúde $466 / 2012^{7}$, que define os procedimentos éticos para pesquisas envolvendo seres humanos. Os participantes foram informados de que teriam direito de se retirar do estudo, se assim desejassem, em qualquer momento da pesquisa. Todos eles assinaram termo de consentimento livre e esclarecido, por meio do qual expressaram, com autonomia, sua concordância em participar do trabalho.

\section{Resultados}

\section{Perfil dos entrevistados}

A amostra deste estudo foi formada por 60 alunos do curso de medicina da Univás, de ambos os sexos, com entre 18 e 31 anos de idade, cursando do primeiro ao sexto ano da graduação (10 estudantes de cada ano). Sobre a experiência com a terminalidade da vida, 50 (83\%) afirmaram já ter algum contato com questões relacionadas ao tema, bem como com a bioética, em disciplinas da graduação. Os participantes apontaram, porém, um grande distanciamento entre as aulas teóricas sobre eutanásia, distanásia e ortotanásia (ministradas no primeiro ano do curso) e o momento da prática.

A partir do terceiro ano, os alunos já relatam experiências práticas com a morte, na disciplina de semiologia, quando se deparam com a divergência entre a matéria estudada e a realidade da relação médico-paciente. No quarto ano, as experiências práticas com a morte se ampliam nas aulas de semiologia e nos estágios, porém sem grandes reflexões, de forma até banalizada. No quinto ano, o internato traz essa vivência de modo rotineiro, entretanto o único aparato teórico para enfrentar as situações são as poucas aulas de bioética do primeiro ano. Já no sexto ano, as experiências com o tema se intensificam, mas, apesar da maior maturidade e vivência, os alunos ainda remetem às aulas que tiveram no primeiro ano, quando não entendiam bem as questões levantadas.
A partir das respostas ao instrumento semiestruturado, ideias centrais foram identificadas e organizadas em um discurso-síntese, redigido na primeira pessoa do singular. A seguir, as mais frequentes dessas ideias centrais, com seus respectivos discursos-síntese, são apresentadas.

\section{Para você, qual o significado de terminalidade da vida?}

Nas respostas a essa pergunta, as ideias centrais que surgiram foram: "fechamento/fim da vida", "passagem do corpo físico para o espiritual", "morte encefálica", "separação corpo-mente-espírito" e "múltiplos fatores". As mais frequentes foram "fechamento/fim da vida" e "passagem do corpo físico para o espiritual".

\section{- Fechamento/fim da vida}

"Eu acho que é um processo natural, uma parte como outra qualquer da vida, como se fosse o fechamento de um ciclo. Terminar a vida é o fim desse ciclo. Seria a parada das funções fisiológicas, batimentos cardíacos e outros órgãos importantes, quando não tem mais o que ser feito a respeito de alguma doença, comorbidade, um problema de saúde em geral" (frequência: 34 ).

\section{- Passagem do corpo físico para o espiritual}

"É uma etapa evolutiva, um momento de passagem do corpo físico para o espiritual, quando se encerra a parte da vida aqui na Terra (e ela continua em algum outro plano, por exemplo)" (frequência: 15).

\section{Qual seria o seu sentimento se tivesse que lidar, neste momento, com um paciente terminal?}

Nas respostas a essa pergunta, surgiram as ideias centrais: "insegurança", "solidariedade", "tristeza, ansiedade e impotência", "inconstância", "angústia, compaixão, frustração e fracasso" e "estarrecimento" As três ideias que apareceram com mais frequência são destacadas a seguir.

\section{- Insegurança}

"Não sei o que eu iria fazer, não sei reagir a essas situações ainda (...). Eu acho que 
não estaria preparado. Hoje eu não teria nenhuma condição de fazer isso [lidar com um paciente terminal], tanto falando da bagagem teórica da faculdade quanto emocional. Tanto a faculdade quanto (...) a vida não ensinam a gente a lidar com perdas" (frequência: 21).

\section{- Solidariedade}

"Eu tentaria fazer de tudo para o bem-estar dele, tentaria ao máximo entrar com um apoio e ver o que seria melhor para amenizar o sofrimento, a dor dele, para que ele passe por esse período da melhor forma possível" (frequência: 15).

\section{- Tristeza, ansiedade e impotência}

"A princípio, eu ficaria meio abalado emocionalmente, um pouco ansioso, entristecido, por causa do sentimento de impotência, de não poder fazer mais nada pela pessoa" (frequência: 9).

\section{Se alguém lhe perguntasse se você se} sente preparado(a) para lidar com a morte e o processo de morrer, o que você diria?

As ideias centrais que surgiram nas respostas a essa questão foram: "não estou preparado", "estou preparado", "nunca se está preparado", "mais ou menos preparado", "depende do vínculo" e "não sei". As três ideias mais frequentes, com seus discursos-síntese, são destacadas a seguir.

\section{- Não estou preparado}

"Não estou preparado, ainda não tive preparo para isso, nem na vida nem na faculdade" (frequência: 25).

\section{- Está preparado}

"Eu estou preparado porque é algo natural, a vida e as experiências nos ensinam" (frequência: 10).

\section{- Nunca se está preparado}

"Nunca estarei totalmente preparado, ninguém está preparado para morrer ou ver o outro morrer" (frequência: 10).
Se alguém lhe perguntasse sobre a abordagem do tema da morte e pacientes terminais na formação médica, o que você diria?

As ideias centrais que sugiram nas respostas a essa pergunta foram: "abordagem superficial", "deveria ser abordado com mais frequência", "tema não abordado", "importante ser abordado" e "não existe preparação". As ideias mais frequentes foram "abordagem superficial" e "deveria ser abordado com mais frequência".

\section{- Abordagem superficial}

"Abordagem bem insatisfatória, não tem nenhuma discussão sobre isso: como lidar, quais são os sentimentos" (frequência: 35 ).

\section{- Deveria ser abordado com maior frequência}

"Eu acho que é muito importante, principalmente em se tratando de medicina; 99\% da nossa carga horária é sobre vida, sendo que todas as áreas lidam com o processo da perda, e nós não temos apoio" (frequência: 14).

\section{Discussão}

Entre as ideias centrais relacionadas ao significado da terminalidade da vida, a noção mais prevalente foi "fechamento/fim da vida", considerado como processo biológico natural, fim de um ciclo orgânico. As escolas de medicina preparam estudantes para se tornarem oficiais-maiores da ciência e gerentes de biotecnologias complexas, passando ao largo de ensinamentos sobre a verdadeira arte de ser médico ${ }^{8}$. Investe-se muito no ensino de aspectos biológicos, mas em detrimento de aspectos psicossociais e espirituais do paciente.

A vida vai muito além do corpo físico, e considerar a biografia do paciente é fundamental para compreender que cada pessoa deixa um legado quando a morte chega. Não somos doentes nem vítimas da morte: somos peregrinos na existência, e isso é saudável. Quando a vida biológica é absolutizada, passa-se a procurar a cura da morte, adiando o inevitável ${ }^{9}$. No próprio discurso dos estudantes, verifica-se a redução do ser humano a sua dimensão biológica: "(...) quando não tem 
mais o que ser feito a respeito de alguma doença, comorbidade, um problema de saúde em geral". A fala reforça a dicotomia entre a doença e a pessoa doente: ao invés do cuidado da pessoa, privilegia-se o tratamento da doença.

Outra ideia central, que parte desse reducionismo, remete à noção de terminalidade da vida como morte cerebral/encefálica. Mas viver não é o mesmo que estar vivo. Viver envolve todos os elementos que compõem o ser humano, enquanto estar vivo remete apenas ao elemento biológico ${ }^{10}$. A medicina mantém o princípio da vida como fim de suas atividades, e por isso as ciências biomédicas lidam de modo mais direto com a questão da ética da técnica. Assim, pressupondo a ideia de responsabilidade com o futuro e medo de colocar a vida humana em risco, propõe-se uma ética da responsabilidade que guie o agir técnico da medicina e não considere o paciente como um objeto. A ciência médica só pode sair do paradigma "coisificante" se partir do primeiro critério de resposta desenvolvido por Hans Jonas ${ }^{11}$, que é o imperativo da vontade motivada e consciente.

A relação do direito de viver com o direito de morrer deve nortear a arte médica, seus direitos e deveres. Essa arte consiste em infligir o mínimo possível dor e degradação, evitando a prolongação não desejada e degradante do processo de extinção da vida. Assim, quando a medicina não aceita o direito de morrer, o médico pode deixar de ser um servidor preocupado com o bem do paciente para se tornar um mestre tirânico ${ }^{11}$.

As demais ideias centrais relacionadas ao significado da terminalidade da vida - "passagem do corpo físico para o espiritual", "separação corpo-mente-espírito" e "múltiplos fatores" se relacionam com a dimensão espiritual, para além do corpo biológico. A Declaração Universal sobre Bioética e Direitos Humanos ${ }^{12}$ tem como fundamento a visão integral do ser humano, em suas dimensões biológicas, psicológicas, sociais, culturais e espirituais. O ser humano é muito mais do que materialidade biológica, e por isso profissionais de saúde devem ser sensíveis, conscientes de um novo modelo - o paradigma biopsicossocial - que se preocupa com todas as dimensões humanas.

A dimensão espiritual é fator de bem-estar, conforto, esperança e saúde ${ }^{13}$. Não se deve, pois, considerar apenas a dor física, já que a terminalidade também traz a dor da existência. É cuidando do ser vulnerável, sobrecarregado pela dor e sofrimento da doença e do fim da vida, que se pode proporcionar uma morte digna, que ajuda a ressignificar a vida diante da finitude ${ }^{13}$.

Em relação aos sentimentos ao lidar com pacientes terminais, as ideias centrais "insegurança" e "inconstância" demonstram que os estudantes vivenciam conflitos diante do sofrimento. O predomínio de aspectos técnicos do manejo de doenças na formação, sem reflexão sobre as emoções envolvidas, acarreta sobrecarga afetiva ${ }^{13}$. Diante da terminalidade da vida, os estudantes estão sujeitos a experimentar sentimentos como insegurança e medo, revelados pelo discurso: "Hoje eu não teria nenhuma condição de fazer isso, tanto falando da bagagem teórica da faculdade quanto emocional".

No início da formação, o acadêmico de medicina tem seu primeiro encontro com a morte durante as aulas de anatomia, por meio de um corpo desvitalizado e desmembrado em peças $^{14}$, destituído de biografia. Esse primeiro contato, feito de maneira despersonalizada, inicia um processo de expropriação dos sentimentos e negação de aspectos existenciais e simbólicos da morte e do morrer ${ }^{15}$.

Devido à formação tecnicista, os estudantes se sentem inseguros ao lidar com a inexorabilidade da morte. Mas a medicina não pode afastar a morte indefinidamente, pois ela é condição da existência humana. Quando já não é possível preservar a vida, a busca obstinada pela cura torna-se fútil. Não poderíamos desejar uma vida física interminável, sem nenhuma qualidade de vida. Já que a morte é inevitável, que seja digna ${ }^{16}$.

O fim da medicina não é apenas a cura, mas o restabelecimento da saúde do corpo, incluindo a saúde psicológica e social. Restabelecer a saúde do paciente implica não só curar a doença, mas também fazê-lo retomar sua vida normal com autonomia, que é muitas vezes perdida no processo da enfermidade ${ }^{17}$.

A ideia central "segurança" foi apresentada por apenas três estudantes, reafirmando que a formação vinculada ao modelo biomédico não é capaz de apoiar os futuros profissionais emocionalmente. Diante da sobrecarga de conteúdos durante a vida acadêmica e do dilema da falta de tempo, muitos médicos apresentam profundo 
abalo, medo, insegurança e depressão ao encarar a morte, passando então a ignorá-la como forma de autoproteção ${ }^{18}$.

As ideias centrais "solidariedade" e "compaixão" remetem a sentimentos humanos muito diferentes. "Compaixão" pode tanto significar atos virtuosos quanto representar uma debilidade moral, caso entendida como exclusão e medicação do paciente por acreditar que conhecemos suas necessidades e demandas antes mesmo dele ter a possibilidade de verbalizar seus reais desejos. Já a solidariedade, como princípio, refere-se a ações que beneficiam o paciente a partir de seu reconhecimento como sujeito autônomo, capaz de fazer escolhas ${ }^{19}$. Muitos profissionais médicos em conflito com esses sentimentos desrespeitam a autonomia e o desejo do paciente.

As ideias centrais "tristeza", "ansiedade", "impotência", "angústia", "frustração e fracasso" e "estarrecimento" demonstram a fragilidade do estudante de medicina diante da complexidade da vida. Para se defender, o futuro profissional desenvolve duas estratégias: a despersonalização do paciente (o médico nega que está lidando com uma pessoa e vê apenas a patologia) e a "onipotência" (desenvolvida quando se começa a acreditar na fantasia de que é possível dominar a vida e a morte). Com a onipotência, o médico acaba por se isolar da equipe e até do próprio paciente, podendo desenvolver distúrbios quando o confronto com a realidade gera frustrações ${ }^{20}$. O profissional de saúde lida com situações de sofrimento e dor, e a presença da morte é constante. Não conseguir evitá-la, podendo apenas aliviar o sofrimento, traz ao profissional a consciência de sua própria finitude ${ }^{21}$.

Sobre o significado da morte e do morrer, entre as ideias centrais que mais se destacaram estão "não estou preparado" e "nunca se está preparado". Nesse tema, são relevantes as reflexões sobre os avanços da ciência, relacionados com o temor e a negação da morte ${ }^{22}$.

Para aprofundar as questões bioéticas relativas à morte, utilizou-se a chamada "trindade bioética": os princípios de autonomia, beneficência e justiça ${ }^{23}$. O princípio da autonomia defende uma relação simétrica entre profissional de saúde e paciente, na qual o paciente assume o protagonismo de sua vida e, ciente de suas condições, toma as próprias decisões. Entretanto, é comum que ocorra o contrário: a relação paternalista, na qual o profissional de saúde, ocupando o lugar do saber, utiliza o princípio de beneficência (fazer o bem e evitar o sofrimento) para agir unilateralmente, determinando o que fazer com o paciente, como e quando. Nesse tipo de relação, o profissional usa como mecanismo de defesa uma abordagem mecânica e despersonalizada, que reprime a ansiedade e rejeita a morte iminente, evitando desnudar falhas, limitações e sua própria mortalidade $^{22}$. Já o princípio da justiça se refere à qualidade do viver, considerando as singularidades e necessidades de cada pessoa. O que é fundamental não é a extensão da vida, mas sim sua qualidade.

Alguns atos que apressam a morte podem ser fruto da solidão dos profissionais, que se sentem sem apoio ao cuidar de pacientes em sofrimento ${ }^{21}$. Essa solidão pode ocorrer inclusive em hospitais movimentados (a solidão na multidão). As pessoas não se enxergam umas às outras nem sabem o que está acontecendo na sala ou no leito ao lado. Em vários hospitais, o fim da vida é pleno de sofrimento, com muitas dores, desumanizado. Diante disso, a sociedade busca ocultar a morte, delegando-a ao médico e ao hospital e a tornando medicalizada, institucionalizada, racionalizada e rotineira ${ }^{24}$.

O médico tornou-se o grande responsável por combater e vencer a morte. A insegurança sentida pelo profissional e a consciência de não se sentir preparado contrastam com essa imagem de grande salvador, institucionalizada desde os primórdios da medicina, mas cada vez mais presente com o advento da medicina científica. Trecho de fala selecionado para ilustrar o problema revela a angústia de se sentir solitário diante da inexorabilidade da morte: "(...) ainda não tive preparo para isso, nem na vida nem na faculdade".

As ideias centrais "estou preparado" e "mais ou menos preparado" evidenciam que as experiências, o amadurecimento e o contato com a terminalidade da vida contribuem com a formação do futuro médico. Estamos todos sujeitos à dor e à doença, e todos tememos a morte, mas essa experiência é vivida de modos muito diferentes, sobre os quais temos o direito e a obrigação de refletir ${ }^{19}$. Por mais interessantes, emocionantes e estimulantes que as coisas do mundo pareçam, elas não se tornam humanas até o momento em que podemos discuti-las com nossos semelhantes ${ }^{5}$. 
Tudo que não é objeto de diálogo pode ser sublime, horrível ou misterioso. Humanizamos o que passa no mundo e em nós quando dialogamos e, com esse diálogo, aprendemos a ser humanos. Somente a partir do encontro é possível transpor a barreira da insegurança e se sentir preparado diante da perspectiva da morte.

A ideia central "depende do vínculo" denota que a criação de vínculos desestabiliza o mecanicismo da ação diante da morte. Profissionais de saúde criam laços com alguns pacientes e, quando estes morrem, entram em um processo de luto não reconhecido, não autorizado ${ }^{25}$. Surge então o conflito entre fugir da morte ou aprender sobre seu processo com os pacientes. A profissão médica é o exercício de uma arte baseada na medicina científica e, como tal, tem como objeto o corpo humano, porém o que realmente importa é o sujeito. O médico tem de tratar, primeiramente, do paciente ${ }^{11}$.

O discurso "acho que tudo depende do grau de relação que a gente tem" retrata justamente a existência do afeto, que humaniza a assistência. A relação médico-paciente é, antes de tudo, uma relação entre sujeitos, e o cuidado surge quando a existência de alguém realmente tem importância. 0 médico então se dedica ao paciente e participa de seu destino, de sua vida ${ }^{26}$.

A ideia central "não sei" retrata o distanciamento da reflexão e da discussão sobre a morte no curso de medicina. Porém, enquanto os profissionais de saúde não entenderem a finitude, não terão condições de estar realmente presentes numa situação de cuidado ${ }^{27}$. A arte médica exige, além de preciosos conhecimentos científicos, a capacidade de escutar para compreender a vulnerabilidade daquele que sofre. No cuidado, o médico utiliza todos os seus conhecimentos e experiências, ainda que não saiba se poderá ou não curar ${ }^{28}$.

Em relação à abordagem do tema da morte e pacientes terminais na formação médica, as ideias centrais que mais se destacaram foram "abordagem superficial" e "deveria ser abordado com mais frequência", ressaltando a necessidade de enfatizar a discussão e a reflexão sobre a morte durante a graduação de medicina.

Pelo que se depreende da análise do instrumento, a morte é apresentada para o estudante de medicina de forma reducionista, privilegiando o biológico e o anatômico em detrimento de aspectos psicológicos, simbólicos e subjetivos, ignorando a biografia do paciente terminal. Desde o início da formação, o estudante aprende que, para compreender uma enfermidade, deve dividir o objeto de seu estudo, seguindo o método científico proposto por Descartes ${ }^{29}$, para quem a busca do saber científico partia do conhecimento das partes.

O discurso "não tem nenhuma discussão sobre isso: como lidar, quais são os sentimentos" denuncia a escassez de reflexão sobre a finitude e a distância em relação aos conflitos existenciais do estudante, também vulnerável, por sua própria condição humana. No trecho "99\% da nossa carga horária é sobre vida, sendo que todas as áreas lidam com o processo da perda, e nós não temos apoio" fica evidente a necessidade de aprofundar a discussão sobre a morte. Para isso, porém, deve-se refletir sobre a vida, pois é por meio da aceitação do ser-para-a-morte que surge o verdadeiro sentido. Aquele que transita poeticamente pela existência, descobrindo algum sentido, provavelmente chegará ao final de forma mais suave e tranquila. Por meio da consciência da finitude, o ser humano é impulsionado à vida.

$\mathrm{Na}$ formação em medicina, muitas vezes o ser humano é descrito simplesmente por seus mecanismos: respiratório, circulatório, digestivo etc. Ensina-se vida em quase a totalidade da carga horária, mas o enfoque biológico reduz o ser humano, fragmentando-o e ignorando dimensões psicológicas, sociais e espirituais. Não se entende a morte como processo natural da vida.

O objetivo da assistência em saúde não é apenas chegar a um diagnóstico, testar uma hipótese ou avaliar a eficácia de um tratamento. A decisão clínica deve ser a mais correta para o doente ${ }^{30}$. O médico que, consciente da impossibilidade de cura, sujeita o paciente a técnicas para prolongar a vida, coisifica o ser humano, viola sua natureza. É preciso compreender que, a partir de determinado momento, o médico deixa de ser a pessoa que cura para se tornar aquela que ajuda o paciente a morrer da maneira menos dolorosa possível ${ }^{31}$. Assim, deve-se respeitar cada paciente, fornecendo menos doses de cura tecnológica e mais cuidado humano.

Sobre a ideia central "tema não abordado", surgiu o discurso: "Esse tema não é abordado especificamente nas aulas. Quanto mais cedo a 
gente tiver essa abordagem, mais cedo a gente vai conseguir pensar sobre o assunto e aceitar $o$ processo". Mais uma vez, desnuda-se a fragilidade da formação médica. Antes de se falar sobre a vida e a morte em sentido filosófico, insere-se o aluno na sala de anatomia, na qual há corpos desmembrados, cheiro de morte, todo um cenário de decomposição do corpo humano.

Essa ausência de reflexão sobre a morte pode formar um profissional tecnicamente impecável, capaz de dominar a alta tecnologia e prolongar a vida, porém inábil na arte de se relacionar com o ser humano e lidar com sua vulnerabilidade diante da finitude. A relação médico-paciente deve ser um momento de encontro entre seres humanos, com todas as suas fragilidades. Daí que, mais além da tecnologia, é preciso ser capaz de considerar as necessidades do paciente e escutar seu sofrimento, ajudando-o a viver ou a morrer, mas sem prolongar inutilmente uma vida vegetativa, desumana ${ }^{22}$.

A ideia central "importante ser abordado" ratifica a necessidade, sentida pelos alunos, de refletir sobre a temática da morte. Se fosse possível ensinar aos estudantes, além do valor da ciência e da tecnologia, o cuidado humano, teríamos grande progresso na arte da medicina ${ }^{22}$.

O discurso "durante a formação, eu acho que falta humanizar, aprendermos a privilegiar o doente sobre a sua doença" mostra a preponderância do modelo biomédico na formação de futuros profissionais. Mas o médico, além de dominar a ciência e a técnica, é um cuidador ${ }^{32}$. Quem cuida e se deixa tocar pelo sofrimento do outro se humaniza e tem a preciosa chance de crescer em sabedoria ${ }^{33}$. Urge, então, uma formação profissional humanista, crítica e reflexiva, baseada em princípios éticos, legais e bioéticos ${ }^{34}$. As práticas humanizadas no campo da saúde, por sua natureza dialógica, não podem ser ensinadas ou aprendidas tecnicamente. Elas estão inseridas em um contexto cultural, ético e estético ${ }^{35}$ e se sustentam nas relações entre indivíduos e coletivos.

A ideia central "não existe preparação" foi apontada por um único estudante, por meio do seguinte discurso: "A gente lida e vai lidar com a morte na profissão (...) Você acaba aprendendo na prática como você deve agir". Isso remete à ideia de que os valores humanistas não são passíveis de aprendizagem, ecoando certa descrença no potencial transformador do processo educativo.
Para fundamentar a importância da educação, vale lembrar a ideia de que mais vale uma cabeça bem-feita do que uma cabeça bem cheia ${ }^{36}$. A cabeça bem cheia acumula conhecimentos sem critérios e sem sentido. Já para a cabeça bem-feita não basta apenas acumular saber, o mais relevante é que o conhecimento leve a decisões adequadas. A educação humaniza o futuro profissional, contribuindo com a construção do sujeito ${ }^{37}$.

\section{Considerações finais}

De todas as inquietações humanas, a mais instigante e causa de maior temor, é a morte. Não tanto pelo fim em si, mas pelo processo de morrer, o medo do desconhecido. A morte está envolta em diversos significados e emoções subjetivas. Hoje, ela ocorre em hospitais, e os profissionais de saúde, em especial o médico, a acompanham. Espera-se, portanto, que esses profissionais estejam preparados para essa vivência.

Embora o compromisso do médico seja com a vida, independentemente de sua competência técnica e conduta ética, a finitude sempre se fará presente. Numa cultura que idealiza o médico como ser capaz de garantir a cura e, consequentemente, a imortalidade das pessoas, quando a morte acontece, afloram sentimentos de fracasso e culpa. A morte do paciente chega a colocar em risco a credibilidade do profissional, o que intensifica seu sentimento de impotência ante a inevitabilidade do fim.

Ao ingressar na faculdade, o estudante de medicina se depara com uma formação tecnicista, quase sempre norteada pela busca obsessiva da cura. Raramente ocorrem momentos de diálogo e reflexão sobre aspectos subjetivos da relação profissional-paciente, que permitam ao estudante expressar seus sentimentos e angústias com relação à morte. No entanto, para a formação do futuro médico, são essenciais habilidades e competências éticas que o modelo biomédico hegemônico não é capaz de ensinar.

Se a morte é inexorável, que seja digna. Para tanto, é necessário promover um cuidado ético, que evite o sofrimento, fortaleça a autonomia e garanta a equidade. Por meio desse cuidado, resgata-se o verdadeiro sentido dos termos gregos therapéuo ("eu cuido") e klinos (reverência ao sofrimento 
humano manifestada com a inclinação sobre o corpo do doente) ${ }^{33}$. O cuidado é um dos pressupostos para garantir a dignidade humana, na vida e na morte.

Todo processo educativo é um processo vivo, em movimento, no qual professor e aluno são responsáveis pelas transformações necessárias para um novo aprendizado. $O$ ato de refletir sobre a práxis pedagógica é importante para colocar em prática uma educação do viver e do morrer. A formação atual não é suficiente para mudar o modelo de assistência ao paciente em fase terminal, visto que as grandes discussões com a sociedade referentes ao cuidado diante da morte ainda não avançaram o suficiente ${ }^{38}$. Refletir sobre a terminalidade da vida não é fácil, uma vez que a hegemonia do modelo biomédico, que busca, muitas vezes obsessivamente, a cura da doença, não se limita aos profissionais de saúde, mas está presente em toda a sociedade.
Esta pesquisa buscou refletir sobre a formação médica em face da complexa temática da educação do viver e, principalmente, do morrer, reconhecendo as dimensões que caracterizam os estudantes como seres humanos com seus sentimentos. Espera-se que a pesquisa tenha enfatizado o bastante a necessidade de mudar não somente a grade curricular do curso de medicina, mas as próprias instituições de ensino, que devem ser espaços de escuta regidos pela ethos (forma de se conduzir, pensar, agir, sentir). Esses espaços precisam promover a abertura à comunicação, a sensibilização para os sentimentos, a escuta e disponibilidade, aprofundando a discussão sobre a morte a fim de diminuir o temor que envolve o assunto e infundir nos estudantes a percepção de que estão preparados para cuidar de pacientes em todos os momentos da vida, inclusive em fase terminal.

\section{Referências}

1. Gomes ALZ, Othero MB. Cuidados paliativos. Estud Av [Internet]. 2016 [acesso 25 jun 2019];30(88):155-66. DOI: $10.1590 / \mathrm{s} 0103-40142016.30880011$

2. Pessini L. Distanásia: até quando investir sem agredir? Bioética [Internet]. 1996 [acesso 25 jun 2019];4(1):31-43. Disponível: https://bit.ly/3eLS6qx

3. Kovács MJ. Profissionais de saúde diante da morte: morte e desenvolvimento humano. São Paulo: Casa do Psicólogo; 1992.

4. Calasans CR, Sá CK, Dunningham WA, Aguiar WM, Pinho STR. Refletindo sobre a morte com acadêmicos de medicina. Rev Bras Neurol Psiq [Internet]. 2014 [acesso 25 jun 2019];18(1):34-57. Disponível: https://bit.ly/2QGjBKb

5. Arendt H. Vidas políticas. Madrid: Taurus; 1980.

6. Lefévre F. Discurso do sujeito coletivo: nossos modos de pensar nosso eu coletivo. São Paulo: Andreoli; 2017.

7. Conselho Nacional de Saúde. Resolução $n^{\circ} 466$, de 12 de dezembro de 2012. Aprova as diretrizes e normas regulamentadoras de pesquisas envolvendo seres humanos. Diário Oficial da União [Internet]. Brasília, p. 59, 13 jun 2013 [acesso 3 maio 2021]. Seção 1. Disponível: https://bit.ly/3eTt6NR

8. Lown B. A arte perdida de curar. São Paulo: JSN; 1996.

9. Pessini L, Bertachini L, editores. Humanização e cuidados paliativos. $4^{a}$ ed. São Paulo: Centro São Camilo; 2009.

10. Almeida AJT. A ortotanásia e a lacuna legislativa. In: Azevedo AV, Ligiera WR, editores. Direitos do paciente. São Paulo: Saraiva; 2012. p. 447-87.

11. Jonas H. Técnica, medicina e ética: sobre a prática do princípio responsabilidade. São Paulo: Paulus; 2016.

12. Organização das Nações Unidas para a Educação, Ciência e Cultura. Declaração Universal sobre Bioética e Direitos Humanos [Internet]. Paris: Unesco; 2005 [acesso 27 mar 2021]. Disponível: https://bit.ly/3u5C2pR

13. Bertachini L, Pessini L. Encanto e responsabilidade no cuidado da vida: lidando com desafios éticos em situações críticas e de final da vida. São Paulo: Paulinas; 2011.

14. Vianna A, Piccelli H. O estudante, o médico e o professor de medicina perante a morte e o paciente terminal. Rev Assoc Med Bras [Internet]. 1998 [acesso 25 jun 2019];44(1):21-7. DOI: 10.1590/S0104-42301998000100005 
15. Zaidhaft S. Morte e formação médica. $2^{a}$ ed. Rio de Janeiro: Francisco Alves; 1990.

16. Jonas H, Lopes WES. O fardo e a benção da mortalidade. Princípios [Internet]. 2010 [acesso 25 jun 2019];16(25):265-81. Disponível: https://bit.ly/3gWNMre

17. Pellegrino E, Thomasma D. Para o bem do paciente: a restauração da beneficência nos cuidados da saúde. São Paulo: Loyola; 2018.

18. Andrade JBC, Sampaio JJC, Farias LM, Melo LP, Sousa DP, Mendonça ALB et al. Contexto de formação e sofrimento psíquico de estudantes de medicina. Rev Bras Educ Med [Internet]. 2014 [acesso 25 jun 2019];38(2):231-42. DOI: 10.1590/S0100-55022014000200010

19. Caponi S. Da compaixão à solidariedade: uma genealogia da assistência médica. Rio de Janeiro: Fiocruz; 2000.

20. Silva ALP, Teixeira MAA. A angústia médica: reflexões acerca do sofrimento de quem cura. Cogitare Enferm [Internet]. 2002 [acesso 25 jun 2019];7(1):75-83. DOI: 10.5380/ce.v7i1.32560

21. Kovács MJ. Bioética nas questões da vida e da morte. Psicol USP [Internet]. 2003 [acesso 25 jun 2019];14(2):115-67. DOI: 10.1590/S0103-65642003000200008

22. Kübler-Ross E. Sobre a morte e o morrer. $10^{\text {a }}$ ed. São Paulo: WMF Martins Fontes; 2017.

23. Pessini L, Barchifontaine CP. Problemas atuais de bioética. São Paulo: Loyola; 1994.

24. Menezes RA. Difíceis decisões: uma abordagem antropológica da prática médica em CTI. Physis [Internet]. 2000 [acesso 25 jun 2019];10(2):27-49. DOI: 10.1590/S0103-73312000000200002

25. Kovács MJ. Instituições de saúde e a morte: do interdito à comunicação. Psicol Ciênc Prof [Internet]. 2011 [acesso 25 jun 2019];31(3):482-503. DOI: 10.1590/S1414-98932011000300005

26. Boff L. Saber cuidar: ética do humano, compaixão pela terra. 10ª ed. Petrópolis: Vozes; 2004.

27. Capena LAB. Os sentimentos dos acadêmicos de medicina no seu enfrentamento com o fenômeno da morte. Porto Alegre: Pontifícia Universidade Católica; 1997.

28. Souza VCT. Bioética, espiritualidade e a arte do cuidar na relação médico-paciente: uma interação da bioética com a teologia. Curitiba: Prismas; 2015.

29. Descartes R. Discurso del método. Ciudad de México: Porrúa; 1984.

30. Pellegrino ED, Thomasma DC. A philosophical basis of medical practice: toward a philosophy and ethic of the healing professions. New York: Oxford University Press; 1981.

31. Jonas H. Le droit de mourir. Paris: Payot \& Rivages; 1996.

32. Tostes MA. (Des)encontro do médico com o paciente: o que pensam os médicos? Rio de Janeiro: Rubio; 2014.

33. Pessini L, Bertachini L, editores. Bioética, cuidado e humanização: sobre o cuidado respeitoso. São Paulo: Centro Universitário São Camilo; 2014.

34. Brasil. Ministério da Educação. Resolução $n^{\circ}$ 3, de 20 de junho de 2014. Institui Diretrizes Curriculares Nacionais do Curso de Graduação em Medicina e dá outras providências. Diário Oficial da União [Internet]. Brasília: Ministério da Educação; 2014 [acesso 2 maio 2020]. Disponível: https://bit.ly/3eRJwpY

35. Silva MR, Sakamoto J, Gallian DMC. A cultura estética e a educação do gosto como caminho de formação e humanização na área da saúde. Trab Educ Saúde [Internet]. 2014 [acesso 25 jun 2019];12(1):15-28. DOI: $10.1590 /$ S1981-77462014000100002

36. Morin E. A cabeça bem-feita: repensar a reforma, reformar o pensamento. Rio de Janeiro: Bertrand Brasil; 2001.

37. Severino AJ. A busca de sentido da formação humana: tarefa da filosofia da educação. Educ Pesqui [Internet]. 2006 [acesso 25 jun 2019];3(2):619-34. DOI: 10.1590/S1517-97022006000300013

38. Silva RCF. Cuidados paliativos oncológicos: reflexões sobre uma proposta inovadora na atenção à saúde [dissertação] [Internet]. Rio de Janeiro: Fiocruz; 2004 [acesso 25 jun 2019]. Disponível: https://bit.ly/3gUHrwn 
Izaura Mariana Sobreiro - Mestre - izaura.sobreiro@hotmail.com

(D) 0000-0001-5855-0601

Priscelly Cristina Castro Brito - Graduanda - pri.brito96@gmail.com

(D) 0000-0002-7613-7711

Adriana Rodrigues dos Anjos Mendonça - Doutora - drijar@hotmail.com

(D) 0000-0003-0526-6636

\section{Correspondência}

Izaura Mariana Sobreiro - Rua Tiradentes, 521, apt. 1, Centro CEP 37550-193. Pouso Alegre/MG, Brasil.

\section{Participação dos autores}

Izaura Mariana Sobreiro foi responsável pela coleta de dados, análise e interpretação dos resultados e produção do texto. Priscelly Cristina Castro Brito contribuiu com a coleta e consolidação dos dados. Adriana Rodrigues dos Anjos Mendonça orientou a pesquisa e colaborou com sugestões e correções do artigo. 